\title{
Effect of design dark fraction on the loss of biomass productivities in photobioreactors
}

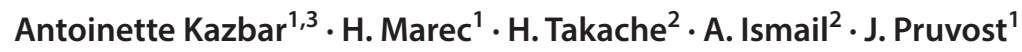

\begin{abstract}
Design dark fraction reflects the unlit part of a microalgal culture system, as for example a hydraulic loop used for temperature or $\mathrm{pH}$ regulation, or a circulating pump for mixing purposes. This study investigates the impact of design dark fraction on photosynthetic biomass productivity of the eukaryotic microalgae Chlorella vulgaris. The effect of the volume of the dark fraction and the residence time spent in this dark fraction was investigated with two different nitrogen sources $\left(\mathrm{N}-\mathrm{NH}{ }_{4}^{+}, \mathrm{N}-\right.$ $\mathrm{NO}_{3}{ }^{-}$). Results showed a decrease of biomass productivity when the volume of the dark fraction and the dark residence time increased. Up to $47 \%$ loss of biomass productivity could be reached for a design dark fraction $f_{\mathrm{d}}=30 \%$ of the total culture system volume. This loss was explained as a result of metabolic reactions related to an increase of respiration activity or a decrease of photosynthetic activity in the cells.
\end{abstract}

Keywords Design dark fraction $\cdot$ Respiration $\cdot$ Microalgae $\cdot$ Photosynthesis

\section{Introduction}

It is known that optimizing performances of a given microalgal culture system consists of enhancing environmental conditions and operation parameters such as $\mathrm{pH}$, temperature, dissolved oxygen concentration, residence time, mixing and light attenuation conditions. Nonetheless, the engineering itself plays also a key role. Pruvost et al. [16] studied in detail the effect of relevant engineering parameters on photobioreactor (PBR) performances. In their study, they emphasized the role of engineering parameters affecting the ability of the PBR to collect light, like its specific illuminated area $a_{\text {light }}$. The role of the design dark fraction $f_{\mathrm{d}}$

1 GEPEA, Université de Nantes, CNRS, UMR6144, bd de l'Université, CRTT, BP 406, 44602 Saint-Nazaire Cedex, France

2 Department of Food Science and Technology, Faculty of Agriculture, Lebanese University, Dekweneh, Beirut, Lebanon

3 Platform for Research and Analysis in Environmental Sciences, Doctoral School of Science and Technology, Lebanese University, Campus Rafic Hariri, P.O Box 5, Hadath-Beirut, Lebanon that can be encountered in some cases was also mentioned. The design dark fraction reflects here the unlit fraction of a culture system, as obtained when adding for example, a dark tank in the hydraulic loop for temperature or $\mathrm{pH}$ regulation, or a pump for mixing purposes. AlgoFilm@ technology [14], and several industrial systems like horizontal photobioreactors (Algatechnologies, Israel, www.algatech.com and A4f, Portugal, www.a4f.pt) present in their design a design dark fraction (Fig. 1). In some cases, this could represent more than $20 \%$ of the PBR illuminated volume.

Torzillo and Seibert [25] underlined the impact of the design dark fraction for an optimal PBR design. According to their study, unlit parts of the culture cause additional light/dark $(L / D)$ cycles with low frequency, which reduce the performance of the PBR. Therefore, it is advisable that the ratio of dark-to-total culture volume should be kept as small as possible $\left(f_{\mathrm{d}} \leq 0.05\right)$. Pruvost et al. [16] hypothesized that a dark fraction volume of $20 \%$ can decrease PBR productivities by a factor of 2 for Chlorella vulgaris. To explain these losses of productivity, co-authors mentioned two effects, namely (i) the impact of the design dark fraction itself with a decrease of light-activated volume, and (ii) the additional loss due to an increased respiration activity.

PBR modelling is useful to relate engineering and operating parameters to culture system performances. One of the key elements is to have a kinetic growth model to predict 


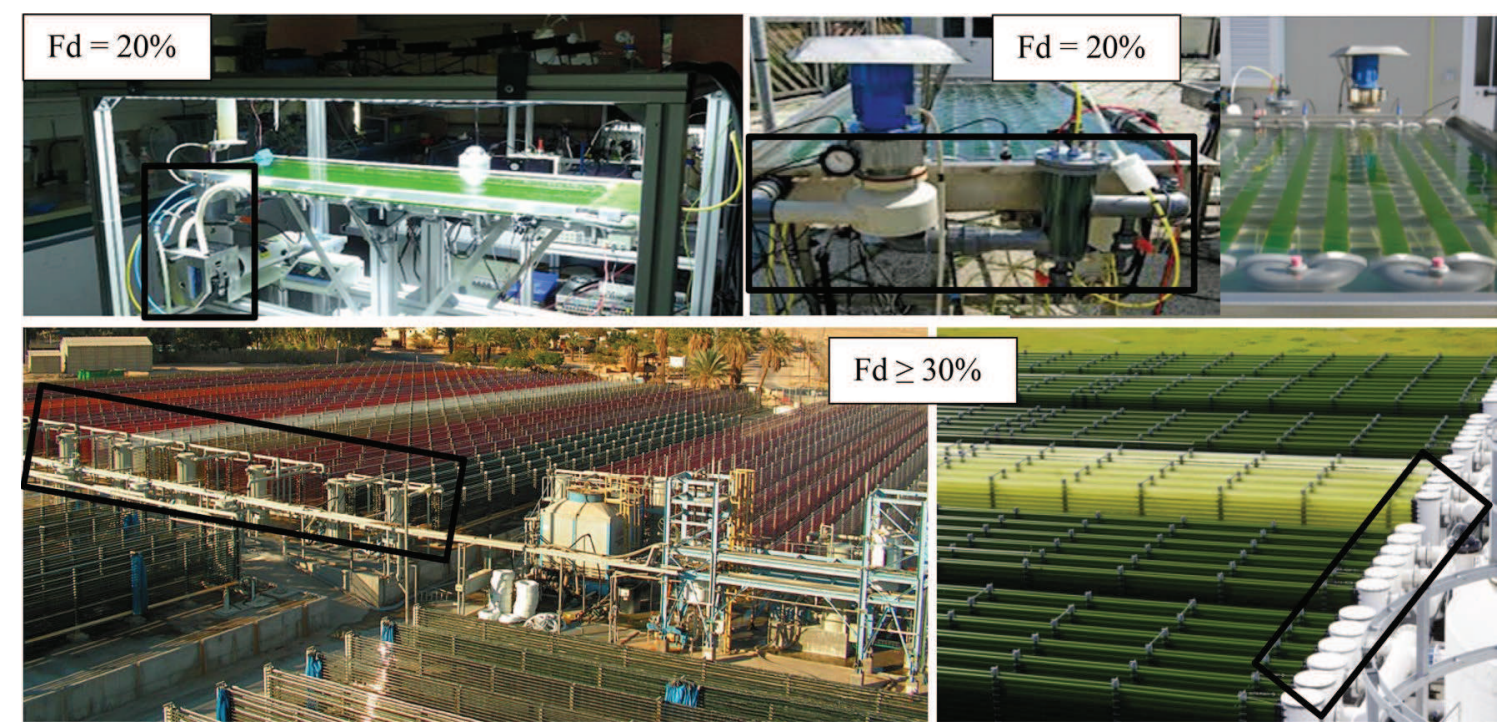

Fig. 1 Examples of lab scale and industrial photobioreactors presenting a design dark fraction. The latter is used for recirculating or degassing purposes as shown in the different photobioreactors geometries

biomass growth rate as a function of culture conditions [15, 20, 22]. This is well known that for microalgae cells, photosynthetic activity is highly related to the light received, which is not homogeneously distributed in the culture volume due to the light attenuation that can occur. The general approach is then to model radiative light transfer, so as to predict light attenuation increase with biomass concentration. But this was not validated for geometries presenting design dark volumes, where full darkness occurs, independent of the biomass concentration (i.e., unlighted volume), and where cells can spend few seconds to several minutes in the dark volume. In the lit part of the PBR, even if a dark zone occurs due to light attenuation along the culture depth, a low light absorption is still present [20]. In addition, due to mixing, the residence time in that zone is usually around few seconds or a less [8]. As a result, the heterogeneous light radiation field in the PBR can be related to a local photosynthetic growth rate, as represented for example by the local specific rate of oxygen production or consumption $J_{\mathrm{O}_{2}}$, which depends on the light received [22]. This value can finally be used to determine resulting growth and then biomass productivity of the culture system.

This study investigates the impact of the design dark fraction on the biomass productivity of the eukaryotic microalgae C. vulgaris by introducing a dark recirculation loop in an airlift PBR. The effect of the volume of the dark loop and the residence time spent in this dark fraction is investigated. Because of its direct influence on respiration activity, the influence of different nitrogen source (ammonia $\mathrm{N}-\mathrm{NH}_{4}{ }^{+}$or nitrate $\mathrm{N}-\mathrm{NO}_{3}{ }^{-}$) on $C$. vulgaris growth is also characterized. Finally, a kinetic growth model adapted to PBR presenting dark fraction is proposed. It allowed determining the specific rate of oxygen production and consumption due to photosynthesis and respiration activity respectively in the entire system (i.e., lit and unlit part). Our results tend to prove the hypothesis of the contribution of respiratory activity on the loss of biomass productivity. Details about $L / D$ cycles contribution will be emphasized in the discussion part of the paper, giving then another possible metabolic response implication.

\section{Methodology}

\section{Photobioreactor setup}

Figure 2a presents the experimental setup of the photobioreactor presenting a design dark fraction: it consists of a 1-1 Flat Panel Airlift (FPA) photobioreactor which has been modified to add a dark recirculation loop with known volume and circulation velocity. The system is composed then of two parts: (i) the airlift photobioreactor which is always illuminated with continuous light $\left(V_{\mathrm{L}}=10^{-3} \mathrm{~m}^{3}\right)$ and (ii) the dark fraction (non-illuminated volume) constituted of black tubes connected to the back of the photobioreactor to create a dark loop. The volume of the dark loop was modified by changing the length of the tube leading to different values of the dark fraction $\left(f_{\mathrm{d}}\right)$. Mixing in the FPA part was ensured by the airlift system (bubbling air in the system). A pump was used for tricking out microalgae from the FPA to the dark loop. The flowrate in the dark recirculation loop was modified to generate different residence time $\left(t_{\mathrm{d}}\right)$ in the dark fraction. 


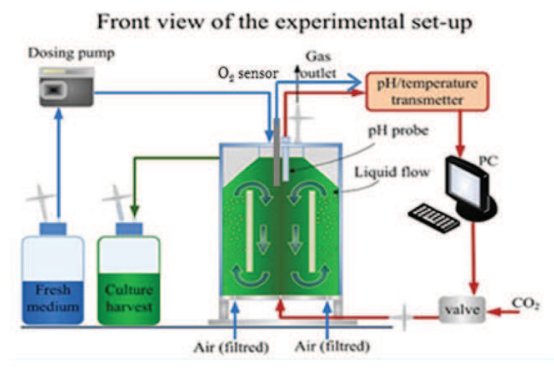

A

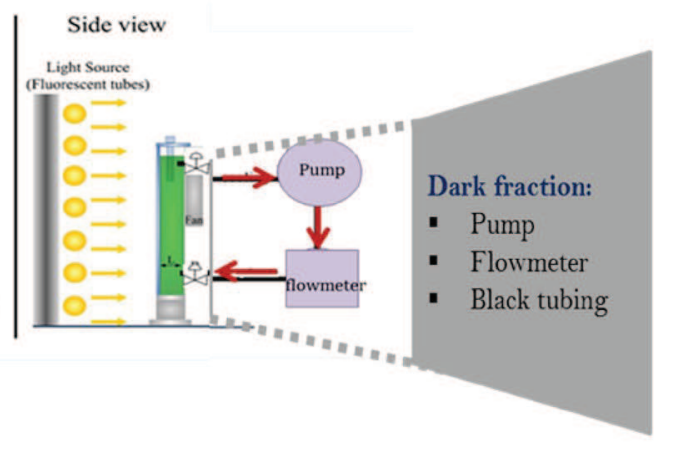

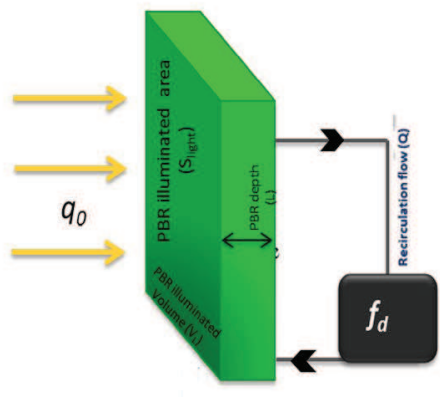

B

Fig. 2 Experimental setup of the photobioreactor presenting a design dark fraction (a) and schematic representation of the system with the flat panel photobioreactor (FPA) as the illuminated volume and $f_{\mathrm{d}}$ the dark volume (b)

As a first step, microalgae were grown in continuous mode with constant photon flux density (PFD) of $250 \mu \mathrm{mol} \mathrm{m} \mathrm{m}^{-2} \mathrm{~s}^{-1}$ and a dilution rate $D$ of $0.02 \mathrm{~h}^{-1}$. Once steady state was reached, samples were taken and dry biomass concentration was determined in addition of the total pigment contents. Inorganic carbon was also measured. Then the dark loop was connected. In this case, microalgae experience an illuminated period (in the FPA) for a while and dark period (in the dark loop) with a known residence time $\left(t_{\mathrm{d}}\right)$. Once steady state was again reached, same measurements as described above were done.

\section{Strain and culture medium}

Chlorella vulgaris CCAP 211-19 [2] is the eukaryotic microalgae cultivated in this study. Its optimal culture parameters are well known and vastly studied [17]. It can be cultivated in different media with different nitrogen source. In this study, C. vulgaris was cultivated in two different autotrophic media: the Sueoka [21] medium using $\mathrm{NH}_{4}{ }^{+}$as nitrogen source, and Bold Basal Medium (BBM) [3] using $\mathrm{NO}_{3}{ }^{-}$as a nitrogen source. Sueoka medium was composed of ( $\mathrm{g} / \mathrm{L}): \mathrm{NH}_{4} \mathrm{Cl} 1.45, \mathrm{MgSO}_{4}, 7 \mathrm{H}_{2} \mathrm{O} 0.281, \mathrm{CaCl}_{2}, 2 \mathrm{H}_{2} \mathrm{O}$ $0.05, \mathrm{KH}_{2} \mathrm{PO}_{4} 0.609, \mathrm{NaHCO}_{3} 1.68$ and $1 \mathrm{~mL}$ of Hutner's trace element solutions. Bold Basal Medium (BBM) was composed of g/L: $\mathrm{NaNO}_{3} 0.75, \mathrm{MgSO}_{4}, 7 \mathrm{H}_{2} \mathrm{O} 0.225, \mathrm{CaCl}_{2}$, $2 \mathrm{H}_{2} \mathrm{O} 0.025, \mathrm{KH}_{2} \mathrm{PO}_{4} 0.123, \mathrm{~K}_{2} \mathrm{HPO}_{4} 0.15, \mathrm{FeSO}_{4}, 7 \mathrm{H}_{2} \mathrm{O}$ 0.014, EDTANa $2,2 \mathrm{H}_{2} \mathrm{O} 0.05, \mathrm{NaHCO}_{3} 1.68$ and $2 \mathrm{~mL}$ of oligoelements solutions.

\section{Determination of biomass dry weight concentration}

Depending on the cell concentration, $0.4-10 \mathrm{~mL}$ of algal suspension was filtered through a pre-dried pre-weighed glass fiber filter (Whatman GF/F, $0.7 \mu \mathrm{m}$ ). Biomass concentrate was washed with distilled water to eliminate minerals. The filter was dried at $110^{\circ} \mathrm{C}$ for $24 \mathrm{~h}$, cooled in a desiccator and reweighed. The final value was the average of three replicates.

\section{Determination of pigment contents}

Culture samples of volume $V_{1}$, were centrifuged $(13,000 \mathrm{~g}$, $\left.10 \mathrm{~min}, 4^{\circ} \mathrm{C}\right)$. The pellet was then suspended in $V_{2}\left(\mathrm{~m}^{3}\right)$ of methanol and then stored in darkness at $44{ }^{\circ} \mathrm{C}$ for $45 \mathrm{~min}$ to allow complete extraction. The cell fragments were then separated by centrifugation $\left(13,000 \mathrm{~g}, 10 \mathrm{~min}, 4{ }^{\circ} \mathrm{C}\right)$ and the optical density of the supernatant containing the pigments dissolved in methanol was measured with a spectrophotometer at 480, 652, 665 and $750 \mathrm{~nm}$ (Jenway, England or Safas MC2, Monaco). Three replicates were prepared, and the chlorophyll a, b, and photoprotective carotenoids (PPC) were determined using the following relationships [18] :

$$
\begin{aligned}
C_{\mathrm{Chla}}= & {\left[-8.0962\left(\mathrm{OD}_{652}-\mathrm{OD}_{750}\right)+16.5169\right.} \\
& \left.\left(\mathrm{OD}_{665}-\mathrm{OD}_{750}\right)\right] \times V_{\text {methanol }} / V_{\text {culture }}, \\
C_{\mathrm{Chlb}}= & {\left[27.4405\left(\mathrm{OD}_{665}-\mathrm{OD}_{750}\right)+12.1688\right.} \\
& \left.\left(\mathrm{OD}_{665}-\mathrm{OD}_{750}\right)\right] \times V_{\text {methanol }} / V_{\text {culture }}, \\
C_{\mathrm{PPC}}= & {\left[4\left(\mathrm{OD}_{480}-\mathrm{OD}_{750}\right)\right] \times V_{\text {methanol }} / V_{\text {culture }} }
\end{aligned}
$$

\section{Determination of inorganic carbon concentration}

Inorganic carbon concentration in the PBR was determined offline using a COTmeter (SHIMADZU TOC5000A, Japan). $10 \mathrm{~mL}$ of a culture sample was taken and filtered with a $0.2-$ $\mu \mathrm{m}$ Minisart ${ }^{\circledR}$ Syringe Filter. These samples were introduced via an injector into a combustion tube. Then inorganic carbon concentration was measured by the analyzer. 


\section{Theory/calculation}

\section{Dark fraction and residence time}

Figure $2 b$ gives an overview of the experimental setup. Dark fraction $\left(f_{\mathrm{d}}\right)$ and residence time $\left(t_{\mathrm{d}}\right)$ are calculated as following:

$f_{\mathrm{d}}=\frac{V_{\mathrm{d}}}{V_{\mathrm{d}}+V_{\mathrm{L}}}$

$t_{\mathrm{d}}=\frac{V_{\mathrm{d}}}{Q}$

$t_{\mathrm{L}}=\frac{V_{\mathrm{L}}}{Q}$

$f_{\mathrm{d}}$ is the design dark fraction, a ratio expressed in this study in percentage of the photobioreactor volume. $t_{\mathrm{d}}(\mathrm{s})$ is the residence time spent by the microalgae in the dark volume $V_{\mathrm{d}}$ and is proportional to the dark volume itself and dependent on the recirculation flow rate $Q\left(\mathrm{~m}^{3} / \mathrm{s}\right)$ in the dark recirculating loop. $t_{\mathrm{L}}$ is the time spent by the microalgae in the lit part of the set-up. It is proportional to the volume of the airlift PBR $\left(V_{\mathrm{L}}\right)$ and dependent on the recirculation flow. Note, however, that this was not possible to determine accurately $t_{\mathrm{L}}$. The illuminated volume can indeed be considered as a well-mixed volume, with then a large set of residence time values. This was not the case in the dark volume, where the tubing flow can be considered in first instance as a plug flow with then a homogeneous residence time, corresponding to $t_{d}$, the time spent in the dark loop.

This is also of interest to introduce the specific illuminated surface-to-volume ratio $\left(a_{\text {light }}\right)$ given as follow:

$a_{\text {light }}=\frac{S_{\text {light }}}{V_{\mathrm{L}}}=\frac{1}{L}$,

where $S_{\text {light }}$ represents the illuminated area of the PBR $\left(\mathrm{m}^{2}\right)$ and $V_{\mathrm{L}}$, the volume of the illuminated photobioreactor $\left(\mathrm{m}^{3}\right)$. $L$ represents the depth of the photobioreactor (m) (Fig. 2b).

\section{Volumetric and surface biomass productivities}

In the case of a culture system operated in continuous mode and with constant light, a steady state can be achieved. Thus, the volumetric biomass productivity $\left(P_{\mathrm{X}}\right)$ is equal to the biomass volumetric growth rate $\left\langle r_{X}\right\rangle$ :

$\frac{\mathrm{d} C x}{\mathrm{~d} t}=0 \rightarrow\left\langle r_{\mathrm{X}}\right\rangle=D \cdot C_{\mathrm{X}}=\frac{1}{\tau} \cdot C_{\mathrm{X}}=P_{\mathrm{X}}$, where $D$ is the dilution rate $\left(\mathrm{h}^{-1}\right), C_{\mathrm{X}}$ is the biomass concentration in $\mathrm{kg} / \mathrm{m}^{3}$ and $P_{\mathrm{X}}$ is the volumetric productivity in $\mathrm{kg} \mathrm{m}^{-3} \mathrm{~h}^{-1}$.

The volumetric productivity $\left(P_{\mathrm{X}}\right)$ is related to surface productivity $\left(P_{\mathrm{S}}\right)$ by the illuminated surface-to-volume ratio $a_{\text {light }}$ (Eq. 7) as followed:

$P_{\mathrm{S}}=\frac{P_{\mathrm{X}}}{a_{\text {light }}}$.

The effect of design dark fraction on the PBR biomass productivity was introduced by Cornet and Dussap [5] who propose an engineering formula to calculate maximal performances of any PBR:

$\overline{P_{\mathrm{X} \max }}=a_{\text {light }}\left(1-f_{\mathrm{d}}\right) \overline{\phi^{\prime}}{ }_{\mathrm{X}} \cdot \rho_{\mathrm{MAX}} \cdot M_{\mathrm{X}} \frac{2 \alpha}{1+\alpha} K \ln \left[1+\frac{q_{0}}{K}\right]$.

In this equation, ${\overline{\phi^{\prime}}}_{\mathrm{X}}, \rho_{\mathrm{MAX}}, K$, and $\alpha$ represent parameters related to the cultivated species (details will be given later). $a_{\text {light }}$ and $f_{\mathrm{d}}$ represent parameters related to PBR geometry.

The influence of the design dark fraction $f_{\mathrm{d}}$ is then considered in Eq. 10. But, according to this rule, the productivity loss is fully proportional to the non-productive dark volume (i.e., a value $f_{\mathrm{d}}=30 \%$ for example should lead to $30 \%$ loss in biomass productivity). Note that, even if an additional loss of performance is induced by for example increasing respiration rates (as shown later), this equation is still valid as its aim is indeed to estimate maximal performance of any culture system.

\section{Light-limited growth and the concept of working illuminated volume fraction}

Several authors introduced the concept of illuminated volume fraction $\gamma$ as a simple way to relate the light absorption conditions to resulting PBR biomass productivity [5, 9, 22]. It is a dimensionless quantity that can be expressed as:

$\gamma=\frac{z\left(A_{\mathrm{c}}\right)}{L}$

where $z\left(A_{\mathrm{c}}\right)$ is the depth at which the rate of photon absorption, RPA, noted $(A)$ in the PBR is equal to the one achieved at the compensation point of photosynthesis of the species, named $A_{\text {c. }}$. The latter corresponds to the minimum amount of energy that is necessary to balance cell respiration or cell maintenance by the photosynthetic activity (i.e., $J_{\mathrm{O}_{2}}=0$ ). Souliès et al. [20] reported $A_{\mathrm{c}}=1200 \mu \mathrm{mol}_{\mathrm{hv}} \mathrm{kg}^{-1} \mathrm{~s}^{-1}$ for C. vulgaris.

An illumination fraction $\gamma=1$ corresponds to the case where the minimum value of RPA in the culture volume corresponds to $A_{\mathrm{c}}$ (which is generally achieved at the backwall of a flat panel PBR for example). This is the most efficient case as all the culture volume received sufficient light energy for positive growth, 
without dark zone where respiration activity prevails. As a consequence, this corresponds then to an average biomass growth rate (or biomass productivity in continuous steady state) of the culture at its maximum [15]. On the other hand, $\gamma<1$ indicates the presence of the so-called dark zone in the culture volume where $A_{\mathrm{c}}(z)<A_{\mathrm{c}}$, with then negative values of the local growth rate. Note that the dark zone related to light attenuation in the illuminated volume, is different from the design dark fraction. The latter corresponds to unlit part of the culture system.

\section{Overview of the kinetic growth model}

Modelling photosynthetic microalgal growth has been widely studied [1]. Pruvost et al. [15] proposed a model that relates light attenuation conditions to photosynthetic growth. It allows predicting photobioreactor performance or productivity variation for operating parameters affecting light-limited cultures (residence time, PFD...). A full description of the model can be found in many co-authors papers. In this paper, only equations needed for the interpretation of results are presented.

This model is based on the determination of the local specific rate of oxygen production $J_{\mathrm{O}_{2}}$ as deduced from the local RPA value $(A)$ :

$J_{\mathrm{O}_{2}}=\rho_{\mathrm{M}} \frac{K_{A}}{K_{A}+A} \overline{\phi^{\prime}}{ }_{\mathrm{O}_{2}} A-\frac{J_{\mathrm{NADH}_{2}}}{v_{\mathrm{NADH}_{2}-\mathrm{O}_{2}}} \cdot \frac{\mathrm{Kr}}{\mathrm{Kr}+A}=J_{\mathrm{O}_{2 \text { photo }}}-J_{\mathrm{O}_{2 \text { resp }}}$,

where $\rho$ is the energy yield for photon conversion of maximum value $\rho_{\mathrm{M}},{\overline{\phi^{\prime}}}_{\mathrm{O}_{2}}\left(\mathrm{~mol}_{\mathrm{O}_{2}} \mu \mathrm{mol}_{\mathrm{hv}}^{-1}\right)$ is the molar quantum yield for the $Z$-scheme of photosynthesis as deduced from the structured stoichiometric equations, $K_{A}\left(\mu \mathrm{mol}_{\mathrm{hv}} \mathrm{kg}^{-1} \mathrm{~s}^{-1}\right)$ is the half-saturation constant for photosynthesis, $J_{\mathrm{NADH}_{2}}$ $\left(\mathrm{mol}_{\mathrm{NADH}_{2}} \mathrm{~kg}^{-1} \mathrm{~s}^{-1}\right)$ is specific rate of cofactor regeneration on the respiratory chain in the light, here linked to oxygen consumption by the stoichiometric coefficient $v_{\mathrm{NADH}_{2}-\mathrm{O}_{2}}$ (the stoichiometric coefficient of cofactor regeneration on the respiratory chain), $K_{\mathrm{r}}\left(\mu \mathrm{mol}_{\mathrm{hv}} \mathrm{kg}^{-1} \mathrm{~s}^{-1}\right)$ is the half-saturation constant describing the inhibition of respiration in light, $J_{\mathrm{O}_{2 \text { photo }}}\left(\mathrm{mol}_{\mathrm{O}_{2}} \mathrm{~kg}^{-1} \mathrm{~s}^{-1}\right)$ is the specific rate of oxygen production due to photosynthesis and $J_{\mathrm{O}_{2 \text { resp }}}\left(\mathrm{mol}_{\mathrm{O}_{2}} \mathrm{~kg}^{-1} \mathrm{~s}^{-1}\right)$ the specific rate of oxygen consumption due to respiration. Local values of oxygen production can be averaged on the culture volume $V_{\mathrm{R}}$.

$J_{\mathrm{O}_{2}}=\frac{1}{V_{\mathrm{R}}} \iiint_{V_{\mathrm{R}}} J_{\mathrm{O}_{2}} \mathrm{~d} V_{\mathrm{R}}$

Consequently, the mean volumetric biomass growth rate $r_{\mathrm{X}}$ can be deduced by:

$r_{\mathrm{X}}=\frac{\left\langle J_{\mathrm{O}_{2}}\right\rangle C_{\mathrm{X}} M_{\mathrm{X}}}{v_{\mathrm{O}_{2-x}}}$
Table 1 Summary of kinetic model parameters of $C$. vulgaris in both medium $\left(\mathrm{N}-\mathrm{NH}_{4}{ }^{+}\right.$and $\left.\mathrm{N}-\mathrm{NO}_{3}{ }^{-}\right)$

\begin{tabular}{llll}
\hline Parameters & Values & \multicolumn{2}{l}{ Unit } \\
\cline { 2 - 3 } & $\mathrm{N}-\mathrm{NH}_{4}{ }^{+}$ & $\mathrm{N}-\mathrm{NO}_{3}^{-}$ & \\
\hline$\rho_{\mathrm{M}}$ & 0.8 & 0.8 & - \\
$J_{\mathrm{NADH}_{2}}$ & $1.8 \times 10^{-3}$ & $1.8 \times 10^{-3}$ & $\mathrm{~mol}_{\mathrm{NADH}_{2}} \mathrm{~kg}^{-1} \mathrm{~s}^{-1}$ \\
$v_{\mathrm{O}_{2}-\mathrm{X}}$ & 1.13 & 1.44 & $\mathrm{~mol}_{\mathrm{O}_{2}} \mu \mathrm{mol}_{\mathrm{hv}}^{-1}$ \\
$\overline{\phi^{\prime}} \mathrm{O}_{2}$ & $1.1 \times 10^{-7}$ & $1.1 \times 10^{-7}$ & $\mathrm{~mol}_{\mathrm{O}_{2}} \mu \mathrm{mol}_{\mathrm{hv}}^{-1}$ \\
$M_{\mathrm{X}}$ & 0.024 & 0.024 & $\mathrm{~kg}_{\mathrm{X}} \mathrm{C}-\mathrm{mol}^{-1}$ \\
$v_{\mathrm{NADH}_{2}-\mathrm{O}_{2}}$ & 2 & 2 & - \\
$K$ & 40,000 & 40,000 & $\mu \mathrm{mol}_{\mathrm{hv}} \mathrm{kg}^{-1} \mathrm{~s}^{-1}$ \\
$K_{\mathrm{r}}$ & 500 & 500 & $\mu \mathrm{mol}_{\mathrm{hv}} \mathrm{kg}^{-1} \mathrm{~s}^{-1}$ \\
$A_{\mathrm{c}}$ & 2800 & 2800 & $\mu \mathrm{mol}_{\mathrm{hv}} \mathrm{kg}^{-1} \mathrm{~s}^{-1}$ \\
$\overline{\phi^{\prime}}{ }_{\mathrm{X}}$ & $2.33 \times 10^{-9}$ & $1.71 \times 10^{-9}$ & $\mathrm{~kg}_{\mathrm{X}} \mu \mathrm{mol}_{\mathrm{hv}}^{-1}$ \\
\hline
\end{tabular}

where $M_{\mathrm{X}}$ is C-molar mass of the biomass $\left(\mathrm{kg} \mathrm{mol}^{-1}\right)$ and $v_{\mathrm{O}_{2-x}}$ the stoichiometric coefficient of oxygen production.

\section{Parameters of the kinetic growth model in different nitrogen source media}

The nitrogen source is well known to affect the overall efficiency of the photosynthetic growth [12]. For ammonium-based medium $\mathrm{N}-\mathrm{NH}_{4}{ }^{+}$, kinetic growth model parameters were determined for $C$. vulgaris by [20]. For nitrate-based medium $\mathrm{N}-\mathrm{NO}_{3}{ }^{-}$, the molar quantum yield for the $Z$-scheme of photosynthesis $\left(\overline{\phi^{\prime}} \mathrm{O}_{2}\right.$ ) was recalculated following Cornet and Dussap [6], based on the stoichiometric growth equations.

The stoichiometric equations of biomass synthesis in nitrate-based medium and ammonium $\mathrm{N}$-source medium are the following:

$$
\begin{aligned}
\mathrm{N} & -\mathrm{NO}_{3}^{-} \text {medium : } \mathrm{HCO}_{3}^{-}+0.9942 \mathrm{H}_{2} \mathrm{O}+0.17 \mathrm{NO}_{3}^{-} \\
& +0.0078 \mathrm{SO}_{4}^{2-}+0.0076 \mathrm{PO}_{4}^{3-} \mathrm{HCH}_{1.78} \mathrm{O}_{0.47} \mathrm{~N}_{0.17} \mathrm{~S}_{0.0078} \mathrm{P}_{0.0076} \\
& +1.4434 \mathrm{O}_{2}+1.208 \mathrm{OH} .
\end{aligned}
$$

This equation was determined with reference to experimental determination of the composition of biomass grown on ammonium medium (experimental determination is not described in this paper).

$$
\begin{aligned}
\mathrm{N} & -\mathrm{NH}_{4}^{+} \text {medium }: \mathrm{HCO}_{3}^{-}+0.494 \mathrm{H}_{2} \mathrm{O}+1.1590 \mathrm{NH}_{4}^{+} \\
& +0.006 \mathrm{SO}_{4}^{2-}+0.007 \mathrm{PO}_{4}^{3-} \mathrm{HCH}_{1.75} \mathrm{O}_{0.413} \mathrm{~N}_{0.159} \mathrm{~S}_{0.006} \mathrm{P}_{0.007} \\
& +1.1295 \mathrm{O}_{2}+0.874 \mathrm{OH}^{-} \text {(Souliés et al. 2016) [20]. }
\end{aligned}
$$

Equations 15 and 16 show that for different nitrogen source the coefficient of oxygen production $\left(v_{\mathrm{O}_{2}-x}\right)$ was not the same. In the case of $\mathrm{N}-\mathrm{NO}_{3}{ }^{-}$medium, $C$. vulgaris produce more oxygen $\left(1.44 \mathrm{~mol}_{\mathrm{O}_{2}} \mathrm{~mol}_{\mathrm{x}}^{-1}\right)$ than in the case of $\mathrm{N}-\mathrm{NH}_{4}{ }^{+}$medium $\left(1.13 \mathrm{~mol}_{\mathrm{O}_{2}} \mathrm{~mol}_{\mathrm{x}}^{-1}\right)$. As a result. the 
quantum yields for the $Z$-scheme of photosynthesis $\left(\overline{\phi^{\prime}}{ }_{\mathrm{O}_{2}}\right)$ for both media were different, and are given in Table 1 as follows [6]:

${\overline{\phi^{\prime}}}_{\mathrm{X}}=\frac{{\overline{\phi^{\prime}}}_{\mathrm{O}_{2}}}{v_{\mathrm{O}_{2}-x}} \times M_{\mathrm{X}}$,

where ${\overline{\phi^{\prime}}}_{\mathrm{O}_{2}}\left(\mathrm{~mol}_{\mathrm{O}_{2}} \mu \mathrm{mol}_{\mathrm{hv}}^{-1}\right)$ is the molar quantum yield for the $Z$-scheme of photosynthesis as deduced from the structured stoichiometric equations and $M_{\mathrm{X}}$ is C-molar mass of the biomass $\left(\mathrm{kg} \mathrm{mol}^{-1}\right)$. The different molar and massic quantum yields for both media will be used for the determination of respiratory and photosynthetic activities according to Eq. 12. According to these equations, we can note that a given amount of absorbed photons is converted to $25 \%$ more biomass in $\mathrm{N}-\mathrm{NH}_{4}{ }^{+}$medium $\left(2.33 \times 10^{-9} \mathrm{~kg}_{\mathrm{X}} \mu \mathrm{mol}_{\mathrm{hv}}^{-1}\right)$ than in $\mathrm{N}-\mathrm{NO}_{3}{ }^{-}$medium $\left(1.71 \times 10^{-9} \mathrm{~kg}_{\mathrm{X}} \mu \mathrm{mol}_{\text {hv }}^{-1}\right)$ (Table 1). This theoretical estimation will be verified experimentally in the next sections.

\section{Experimental determination of respiration and photosynthetic terms}

In the case of photobioreactors presenting design dark fraction, the overall volume of the PBR $\left(V_{\mathrm{R}}\right)$ can be divided into two different volumes, with namely the volume of the lit $\operatorname{PBR}\left(V_{\mathrm{L}}\right)$ and the volume of the dark fraction $\left(V_{\mathrm{D}}\right)$. Both are related to the design dark fraction $\mathrm{f}_{\mathrm{d}}$ and total culture volume $V_{\mathrm{R}}=V_{\mathrm{D}}+V_{\mathrm{L}}$, with $V_{\mathrm{L}}=\left(1-f_{\mathrm{d}}\right) \cdot V_{\mathrm{R}}$ and $V_{\mathrm{D}}=f_{\mathrm{d}} \cdot V_{\mathrm{R}}$.

In the illuminated volume $V_{\mathrm{L}}$, local values of the photosynthetic growth rate $\left(J_{\mathrm{O}_{2} \mathrm{~L}}\right)$ are calculated following Eq. 12 . Therefore,

$J_{\mathrm{O}_{2} \mathrm{~L}}=J_{\mathrm{O}_{2 \text { photo }} \mathrm{L}}-J_{\mathrm{O}_{2 \text { resp }} \mathrm{L}}$,

where local values of the oxygen production rate due to photosynthesis are given by $J_{\mathrm{O}_{2 \text { photo }} \mathrm{L}}=\rho_{\mathrm{M}} \frac{K_{A}}{K_{A}+A} \overline{\varphi_{\mathrm{O}_{2}}^{\prime}} A$ and the oxygen consumption rate due to respiration at light is given by $J_{\mathrm{O}_{2 \text { resp }} L}=\frac{J_{\mathrm{NADH}_{2}}}{v_{\mathrm{NADH}_{2}-\mathrm{O}_{2}}} \cdot \frac{K_{\mathrm{r}}}{K_{\mathrm{r}}+A}$ (Eq. 12).

The corresponding averaged value on the illuminated volume is then given by:

$J_{\mathrm{O}_{2} \mathrm{~L}}=\frac{1}{V_{\mathrm{L}}} \iiint_{V_{\mathrm{L}}} J_{\mathrm{O}_{2} \mathrm{~L}} \mathrm{~d} V_{\mathrm{L}}=J_{\mathrm{O}_{2 \text { photo }} \mathrm{L}}-J_{\mathrm{O}_{2 \text { resp }} \mathrm{L}}$.

In the dark volume, no photosynthesis will occur with only a contribution of respiration activity. We can also assume in first instance a homogenous value of this respiration activity in the entire dark recirculating loop noted $J_{\mathrm{O}_{2 \text { resp }} \mathrm{D}}$ (with $J_{\mathrm{O}_{\text {2resp }} \mathrm{D}}>0$ ). Note that respiratory activity could be different as the one achieved in the light $J_{\mathrm{O}_{\text {2resp }} \mathrm{L}}$, as full darkness is here applied, and then respiration activity at light could then be different.

Thus, the oxygen production rate could be rewritten to represent the overall oxygen production rate $\left(J_{\mathrm{O}_{2} t}\right)$ in the total culture system $V_{\mathrm{R}}=V_{\mathrm{D}}+V_{\mathrm{L}}$.

$$
\begin{aligned}
J_{\mathrm{O}_{2} t} & =\left(1-f_{\mathrm{d}}\right) \cdot J_{\mathrm{O}_{2} \mathrm{~L}}-f_{\mathrm{d}} \cdot J_{\mathrm{O}_{2 \text { resp }} \mathrm{D}} \\
& =\left(1-f_{\mathrm{d}}\right) \cdot\left(J_{\mathrm{O}_{2 \text { photo }} \mathrm{L}}-J_{\mathrm{O}_{2 \text { resp }} \mathrm{L}}\right)-f_{\mathrm{d}} J_{\mathrm{O}_{2 \text { resp }} \mathrm{D}} .
\end{aligned}
$$

Same approach can be applied to calculate corresponding respiration terms. We denote by respiration terms the specific rate of oxygen consumption (i) in the light so in the illuminated FPA $J_{\mathrm{O}_{2 \text { resp }} \mathrm{L}}$, (ii) in the dark fraction $J_{\mathrm{O}_{2 \text { resp }} \mathrm{D}}$ and (iii) on the overall culture system $J_{\mathrm{O}_{\text {2resp }} t}$.

Similar to Eq. 20, those terms are related by:

$J_{\mathrm{O}_{\text {2resp }} t}=\left(1-f_{\mathrm{d}}\right) J_{\mathrm{O}_{2 \text { resp }} L}+f_{\mathrm{d}} J_{\mathrm{O}_{2 \text { resp }} D}$

where $J_{\mathrm{O}_{\text {2resp }} t}$ is the total respiratory activity on the overall system, that is the result of respiratory activity in the illuminated volume $\left(J_{\mathrm{O}_{\text {2resp }} L}\right)$ and of a respiratory activity in the dark fraction $\left(J_{\mathrm{O}_{\text {2resp }} D}\right)$.

$J_{\mathrm{O}_{2 \text { resp }} L}$ is calculated from the kinetic model. It corresponds to the average value in the illuminated volume of local terms $\left(J_{\mathrm{O}_{2 \text { resp }} L}=\frac{J_{\mathrm{NADH}_{2}}}{v_{\mathrm{NADH}_{2}-\mathrm{O}_{2}}} \cdot \frac{K_{\mathrm{r}}}{K_{\mathrm{r}}+A}\right)$ in the Eq. 18. $J_{\mathrm{O}_{2 \text { resp }} D}$ cannot be determined directly, but it can be deduced from experimental data. In steady state, while dark fraction is connected, experimental volumetric productivity $P_{\mathrm{X}}$ is measured and corresponding rate of net oxygen production $J_{\mathrm{O}_{2}}$ can then be deduced using Eq. $14\left(r_{\mathrm{X}}=P_{\mathrm{X}}\right.$ at steady state). Once $J_{\mathrm{O}_{\text {2resp }} L}$ is known, $J_{\mathrm{O}_{2 \text { resp }} D}$ could then be retrieved from Eq. 20. This leads to:

$J_{\mathrm{O}_{2 \text { resp }} D}=\frac{1}{f_{\mathrm{d}}}\left[\left(1-f_{\mathrm{d}}\right) J_{\mathrm{O}_{2} L}-J_{\mathrm{O}_{2}}\right]=\frac{1}{f_{\mathrm{d}}}\left[\left(1-f_{\mathrm{d}}\right) J_{\mathrm{O}_{2} L}-\frac{P_{\mathrm{X}} \cdot v_{\mathrm{O}_{2}-x}}{C_{\mathrm{X}} \cdot M_{\mathrm{X}}}\right]$.

Photosynthetic term in the system presenting a design dark fraction is calculated as follows:

$J_{\mathrm{O}_{2 \text { photo }} t}=\left(1-f_{\mathrm{d}}\right) J_{\mathrm{O}_{2 \text { photo }} L}+f_{\mathrm{d}} J_{\mathrm{O}_{2 \text { photo }} D}$,

where $J_{\mathrm{O}_{2 \text { phot }} D}$, the mean rate of oxygen production in the unlit part of the system is equal to zero; microalgae are in total darkness, photosynthesis could not occur. $J_{\mathrm{O}_{2 \text { photo }} L}$ is calculated following Eq. 1 with the kinetic model parameters presented in Table 1. 


\section{Results and discussion}

\section{Effect of dark fraction on the growth of $C$. vulgaris in ammonium medium}

\section{Effect of dark fraction on the biomass loss of $C$. vulgaris}

For this study, the two dark fraction volumes investigated were $10 \%$ and $30 \%$ of the total volume of the photobioreactor, respectively.

Table 2 shows a clear effect of the dark fraction on the surface biomass productivity for $C$. vulgaris in Sueoka medium $\left(\mathrm{N}-\mathrm{NH}_{4}{ }^{+}\right)$. A loss of $28 \%$ and $40 \%$ on productivity was obtained for the same residence time in the dark loop $\left(t_{\mathrm{d}}=45 \mathrm{~s}\right)$ and for $f_{\mathrm{d}}=10 \%$ and $30 \%$, respectively. For a larger residence time $t_{\mathrm{d}}=300 \mathrm{~s}, 37 \%$ and $47 \%$ of productivity were lost for a $f_{\mathrm{d}}=10 \%$, and $f_{\mathrm{d}}=30 \%$, respectively.

In all cases, a high loss of biomass productivities was then obtained, higher than the one related to the only decrease of the photosynthetically active part of the total culture volume. Increasing the dark fraction leads indeed to an increase in the loss of productivity, with $P_{\mathrm{S}}<P_{\mathrm{S}\left(f_{\mathrm{d}}=0\right)}\left(1-f_{\mathrm{d}}\right)$ (Table 2$)$. Our results confirm then that a design dark fraction leads to a negative impact on the microalgae growth due to the decrease of the illuminated part of the PBR (i.e., $1-f_{\mathrm{d}}$, Eq. 10) with an additional metabolic process leading to a more important loss. We suppose that this process could be an increase of the respiratory activity. This hypothesis will be further investigated in next section.

\section{Respiratory activity for different dark fractions}

Total respiration rate (oxygen consumption rate due to respiratory activity) $J_{\mathrm{O}_{2 \text { resp }} t}$ was calculated for each experiment. This was obtained from Eq. 21. Respiration rates in the lit FPA $J_{\mathrm{O}_{\text {2resp }} L}$ and in the design dark fraction $J_{\mathrm{O}_{\text {resp }} D}$ were calculated following Eqs. 18 and 22, respectively. These rates were determined for each design dark fraction volume $f_{d}$ and residence time in the dark $t_{\mathrm{d}}$.

Table 3 shows a clear relation between the increase of total respiration activity $\left(J_{\mathrm{O}_{2 \text { resp }} t}\right)$ and the loss of biomass productivity $\left(P_{\mathrm{S}}\right)$. Increasing the residence time in the dark fraction leads to an increase of the respiration rates, leading then to a decrease in biomass productivity. For the same $f_{\mathrm{d}}=30 \%$, the total respiration rate, $J_{\mathrm{O}_{\text {2resp }} t}$, increases from $0.2671 \mathrm{~mol}_{\mathrm{O}_{2}} \mathrm{~kg}^{-1} \mathrm{~h}^{-1}$ to 0.3157 then 0.5435 mol $_{\mathrm{O}_{2}} \mathrm{~kg}^{-1} \mathrm{~h}^{-1}$ for a $t_{\mathrm{d}}=45 \mathrm{~s}$ and $300 \mathrm{~s}$, respectively. In the dark fraction, the respiration rate $J_{\mathrm{O}_{\text {2resp }} D}$ increases proportionally to the dark residence time $t_{\mathrm{d}}$; for a same design dark fraction; $J_{\mathrm{O}_{\text {2resp }} D}$ increases from 2.07 to $3.2 \mathrm{~mol}_{\mathrm{O}_{2}} \mathrm{~kg}^{-1} \mathrm{~h}^{-1}$ for a $t_{\mathrm{d}}=45 \mathrm{~s}$ and $300 \mathrm{~s}$, respectively, for a design dark fraction $f_{\mathrm{d}}=10 \%$. Following these observations, the passage of cells from the lit FPA to the design dark fraction can be compared to light/dark cycles with low frequencies [23, 25]. Our system can indeed be represented by two sub-systems; a plugflow reactor representing the dark fraction and a continuous well-mixed stirred tank reactor representing the illuminated photobioreactor (Fig. 3). Microalgal cells will experience then paths between light and dark volumes. The light/dark cycles effect has been discussed in the context of mixing influence on photosynthetic conversion in fully illuminated PBR (i.e., no dark fraction) $[8,13,23]$. In this case, because of high biomass concentrations, a dark zone appears and due to mixing regime, algae travel through the dark and the illuminated zones in the lit PBR but also from the dark fraction to the illuminated FPA. In Takache et al. [23], the response of the microalgae Chlamydomonas reinardtii to the light fluctuations was explained according to Terry [24] by introducing two main ideal responses; with full integration and without integration. The former consider that cells are not sensitive to light variations and the culture only perceives an average light. Conversely, if the culture instantaneously responds when moving from illuminated to dark volume, the response is named without integration, and dark period will have a proportional negative impact on biomass productivity occurred (Fig. 3). The explanation of exact effect of $L / D$
Table 2 Results of different surface productivities of $C$. vulgaris grown in photobioreactor for two design dark fraction volumes $(10 \%$ and $30 \%$ ) and two different residence time $t_{\mathrm{d}}(45 \mathrm{~s}$ and $300 \mathrm{~s})$

\begin{tabular}{|c|c|c|c|c|}
\hline$f_{\mathrm{d}}, t_{\mathrm{d}}$ & Nitrogen source & $\begin{array}{l}P_{\mathrm{S}} \\
\left(\mathrm{g} \mathrm{m}^{-2} \mathrm{~d}^{-1}\right)\end{array}$ & $\begin{array}{l}\text { Condition of design dark fraction due to the } \\
\text { only decrease of illuminated volume (Eq. 10) }\end{array}$ & $\begin{array}{l}\text { Experimental } \\
\text { productivity } \\
\text { loss }\end{array}$ \\
\hline $0 \%$ & $\mathrm{~N}-\mathrm{NH}_{4}{ }^{+}$ & 21 & - & - \\
\hline $10 \%, 45 \mathrm{~s}$ & $\mathrm{~N}-\mathrm{NH}_{4}^{+}$ & 15 & $10 \%$ & $28 \%$ \\
\hline $30 \%, 45 \mathrm{~s}$ & $\mathrm{~N}-\mathrm{NH}_{4}^{+}$ & 12.6 & $30 \%$ & $40 \%$ \\
\hline $10 \%, 300 \mathrm{~s}$ & $\mathrm{~N}-\mathrm{NH}_{4}{ }^{+}$ & 13 & $10 \%$ & $37 \%$ \\
\hline $30 \%, 300 \mathrm{~s}$ & $\mathrm{~N}-\mathrm{NH}_{4}^{+}$ & 11 & $30 \%$ & $47 \%$ \\
\hline
\end{tabular}

Microalgae was grown in continuous mode for a light-intensity $\mathrm{PFD}=250 \mu \mathrm{mol} \mathrm{m} \mathrm{m}^{-2} \mathrm{~s}^{-1}$ and dilution rate $D=0.02 \mathrm{~h}^{-1}$. Experimental productivity loss in addition of the theoretical loss due to the decrease of photosynthetically active volume of the PBR are presented 
Table 3 Results of surface productivity of C. vulgaris grown in two different media $\left(\mathrm{N}-\mathrm{NH}_{4}{ }^{+}\right.$and $\left.\mathrm{N}-\mathrm{NO}_{3}{ }^{-}\right)$for different dark fraction volume $\left(f_{\mathrm{d}}\right)$ and residence time $\left(t_{\mathrm{d}}\right)$ for both cases

\begin{tabular}{|c|c|c|c|c|c|c|c|c|c|}
\hline$f_{\mathrm{d}}$ & $t_{\mathrm{d}}(\mathrm{s})$ & $\begin{array}{l}\text { Nitrogen } \\
\text { source }\end{array}$ & $\begin{array}{l}J_{\mathrm{O}_{2 \text { resp }} t} \\
\left(\mathrm{~mol}_{\mathrm{O}_{2}} \mathrm{~kg}^{-1} \mathrm{~h}^{-1}\right)\end{array}$ & $\begin{array}{l}J_{\mathrm{O}_{\text {2resp }} D} \\
\left(\mathrm{~mol}_{\mathrm{O}_{2}} \mathrm{~kg}^{-1} \mathrm{~h}^{-1}\right)\end{array}$ & $\begin{array}{l}J_{\mathrm{O}_{\text {2resp }} L} \\
\left(\mathrm{~mol}_{\mathrm{O}_{2}} \mathrm{~kg}^{-1} \mathrm{~h}^{-1}\right)\end{array}$ & $\begin{array}{l}J_{\mathrm{O}_{2 \text { photo }} L} \\
\left(\mathrm{~mol}_{\mathrm{O}_{2}} \mathrm{~kg}^{-1} \mathrm{~h}^{-1}\right)\end{array}$ & $\begin{array}{l}J_{\mathrm{O}_{2 \text { photo }} t} \\
\left(\mathrm{~mol}_{\mathrm{O}_{2}} \mathrm{~kg}^{-1} \mathrm{~h}^{-1}\right)\end{array}$ & $P_{\mathrm{s}}\left(\mathrm{g} \mathrm{m}^{-2}\right.$ day $\left.^{-1}\right)$ & $\gamma$ \\
\hline 0 & 0 & $\mathrm{~N}-\mathrm{NH}_{4}{ }^{+}$ & 0.2671 & - & 0.2671 & 1.21 & 1.21 & 21 & 0.33 \\
\hline $30 \%$ & 45 & $\mathrm{~N}-\mathrm{NH}_{4}^{+}$ & 0.3157 & 1.0122 & 0.1315 & 1.9 & 1.34 & 12.6 & 0.56 \\
\hline $30 \%$ & 300 & $\mathrm{~N}-\mathrm{NH}_{4}{ }^{+}$ & 0.5435 & 1.4338 & 0.1595 & 2.15 & 1.48 & 11 & 0.7 \\
\hline $10 \%$ & 45 & $\mathrm{~N}-\mathrm{NH}_{4}{ }^{+}$ & 0.5291 & 2.07 & 0.35 & 1.63 & 1.47 & 15 & 0.5 \\
\hline $10 \%$ & 300 & $\mathrm{~N}-\mathrm{NH}_{4}{ }^{+}$ & 0.73 & 3.28 & 0.45 & 1.86 & 1.67 & 13 & 0.55 \\
\hline 0 & 0 & $\mathrm{~N}-\mathrm{NO}_{3}^{-}$ & 0.16 & - & 0.16 & 1.44 & 1.44 & 17 & 0.4 \\
\hline $10 \%$ & 40 & $\mathrm{~N}-\mathrm{NO}_{3}^{-}$ & 0.167 & 0.45 & 0.14 & 1.46 & 1.43 & 16.3 & 0.42 \\
\hline $20 \%$ & 30 & $\mathrm{~N}-\mathrm{NO}_{3}^{-}$ & 0.17 & 0.61 & 0.06 & 1.82 & 1.45 & 13 & 0.54 \\
\hline $20 \%$ & 40 & $\mathrm{~N}-\mathrm{NO}_{3}^{-}$ & 0.26 & 0.93 & 0.09 & 1.92 & 1.54 & 12 & 0.6 \\
\hline
\end{tabular}

Microalgae is grown in continuous mode for a light-intensity $\mathrm{PFD}=250 \mu \mathrm{mol} \mathrm{m} \mathrm{m}^{-2} \mathrm{~s}^{-1}$ and dilution rate $D=0.02 \mathrm{~h}^{-1}$. Total respiration rate $J_{\mathrm{O}_{2 \text { resp }}}$, respiration rate in the dark $J_{\mathrm{O}_{\text {2resp }} D}$, respiration rate in the lit FPA $J_{\mathrm{O}_{\text {2resp }} L}$, photosynthetic rate in the lit FPA $J_{\mathrm{O}_{2 \text { photo }} L}$ and total photosynthetic rate $J_{\mathrm{O}_{2 \text { phot }} t}$ are calculated thanks to the kinetic growth model by taking into consideration the massic quantum yield for both media $\overline{\phi^{\prime}}$. The illuminated fraction volume was calculated for each point

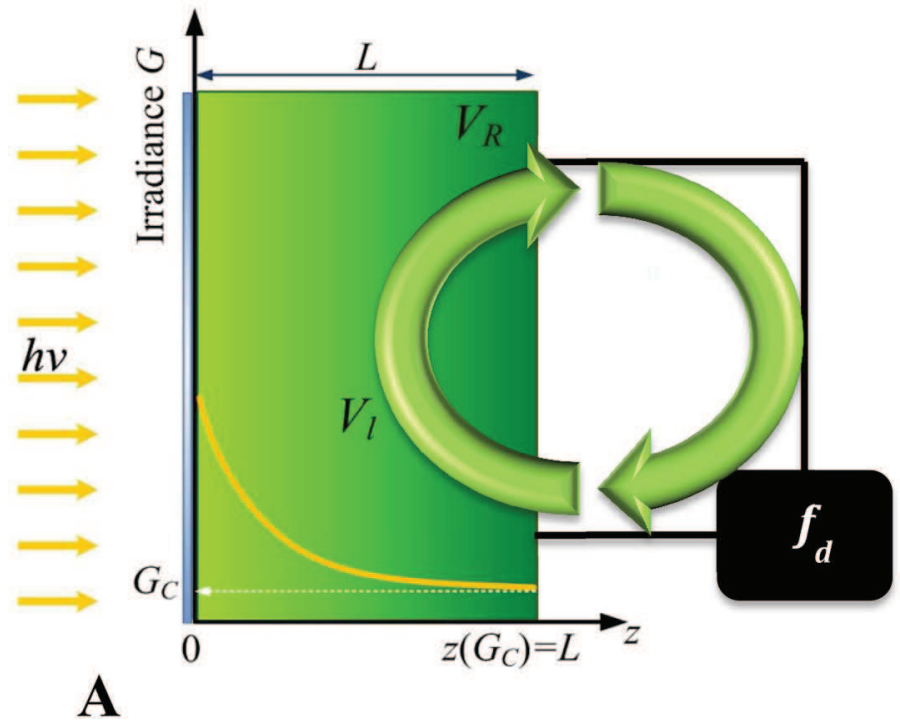

Fig. 3 Schematic representation of the light/dark cycles analogy in the system. The letter is composed of the flat panel Airlift PBR representing the illuminated volume and the design dark fraction representing the dark volume. Microalgae circulate from an illuminated

cycles on the overall metabolism is still unclear. Recently, Graham et al. [7] investigated the penalty on photosynthetic growth in fluctuating light. Their study showed that the regulation of photosynthesis imposes a penalty on growth of the two microalgae Synechococcus elongatus and Chlamydomonas reinhardtii when light/dark cycles occured. This was concluded for low frequencies of fluctuating light between 0.01 and $0.1 \mathrm{~Hz}$. Authors demonstrated that the partial activation state of the Calvin cycle is responsible for the frequency-dependent penalty affecting photosynthetic organisms. Therefore, our hypothesis about respiratory

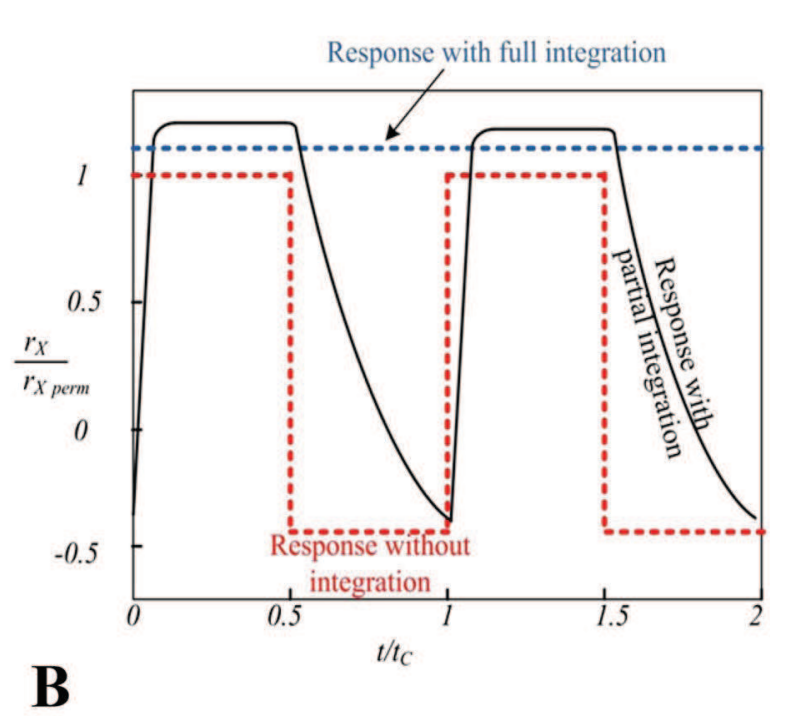

volume to a dark volume (a). Different responses of microalgae cells exposed to different cycle times are presented by Takache et al. [23] (b)

activity impact is no longer reliable, and since no experimental direct measurement of respiration activity or photosynthetic activity was done, interpretations from literature have been considered. In the case of prolonged dark incubation, in the order of hours, Blanken et al. [4] found that cellular respiration decreases. Same observations were concluded in the paper of Kliphuis et al. [11] where respiration of a batch culture of Chlorella sorokiniana was monitored. Their results showed that while the biomass density and the dark zone increased, the cellular respiration went down. These studies contradict our hypothesis of the contribution 
of respiratory activity supporting thus another hypothesis of a decrease of photosynthetic efficiency due to the design dark fraction, leading then to the loss of biomass productivity. In Table 3, total oxygen production rate due to photosynthesis was calculated $J_{\mathrm{O}_{2 \text { photo }} t}$ following Eq. 23. Its values slightly increased when the design dark fraction was added. For an $f_{\mathrm{d}}=30 \%$, it increases from $1.21\left(f_{\mathrm{d}}=0\right)$ to 1.34 to $1.48 \mathrm{~mol}_{\mathrm{O}_{2}} \mathrm{~kg}^{-1} \mathrm{~h}^{-1}$ for a $t_{\mathrm{d}}=45 \mathrm{~s}$ and $300 \mathrm{~s}$, respectively. Otherwise, the oxygen production rate in the lit FPA $J_{\mathrm{O}_{2 \text { photo }} L}$ increased from $1.21\left(f_{\mathrm{d}}=0\right)$ to 1.9 to $2.15 \mathrm{~mol}_{\mathrm{O}_{2}} \mathrm{~kg}^{-1} \mathrm{~h}^{-1}$ for a $t_{\mathrm{d}}=45 \mathrm{~s}$ and $300 \mathrm{~s}$, respectively. This is explained by a modification of light attenuation conditions because of the change in biomass concentration, as explained by the direct effect of both $f_{\mathrm{d}}$ and $t_{\mathrm{d}}$ on resulting overall growth rate. Lower biomass concentration decreases light attenuation and then increases resulting photosynthetic rates in the illuminated volume. This modification of attenuation light condition was confirmed when calculating the illuminated fraction $\gamma$ by Eq. 11 (Table 3). The illuminated fraction $\gamma$ was found to increase when the design dark fraction was connected, confirming an overall decrease of biomass concentration which resulted in a modification of growing conditions also in the lit FPA.

All those analyses suggest that improving the model with experimental measurements can be a track for a better understanding. Parameters related to photosynthetic activity $\left(K_{A}\right.$ ,$\left.\overline{\varphi_{\mathrm{O}_{2}}^{\prime}}\right)$ were probably affected. At this stage, even if an increase of respiration activity in our model would be sufficient to represent dark fraction effect, this is indeed impossible to confirm that the productivity loss due to the dark fraction is due to either an increase of respiration activity, or a decrease of photosynthetic one.

\section{Effect of nitrogen source}

Table 3 presents results obtained with nitrate-based medium (i.e., BBM). Results show that in the case of photobioreactors without dark fraction, a higher productivity for ammonium medium was reached. Biomass productivity $P_{\mathrm{S}}$ was around $20 \%$ higher in ammonium medium than in nitrate medium. This is indeed well known that ammonium uptake and assimilation request less cellular energy for its uptake [12]. When nitrate is used as a nitrogen source, the former is indeed first reduced to nitrite by an energy-requiring reaction catalyzed by nitrate reductase followed by the reduction to ammonium by ATP-dependent or energy-dependent nitrite reductase where it is finally synthetized into amino-acids $[10,12,19]$. This requests then more cellular energy than the direct assimilation of $\mathrm{NH}_{4}{ }^{+}$, resulting finally in a decrease in biomass productivity of around $20 \%$ when compared to a nitrate source for same illumination conditions. Note that this is in agreement with the decrease of the quantum yield of the Z-scheme of photosynthesis as reported in Table 1.

When adding the design dark fraction, it can observed that with $f_{\mathrm{d}}=10 \%$, only a limited effect on the growth of $C$. vulgaris was obtained in the case of nitrate as nitrogen source. Experimentally speaking, the initial biomass productivity was $17 \mathrm{~g} \mathrm{~m}^{-2}$ day $^{-1}$ without a dark fraction $\left(f_{\mathrm{d}}=0\right)$, and the loss did not exceed $6 \%$ when the design dark fraction was added to the PBR volume $\left(16 \mathrm{~g} \mathrm{~m}^{-2} \mathrm{day}^{-1}\right)$. We can note, however, that for a $f_{\mathrm{d}}=20 \%, 28 \%$ loss in productivity occurred for same duration in the design dark fraction. When comparing total rates of oxygen consumption and oxygen production, same observations could be drawn comparing to the case of using nitrate medium. $J_{\mathrm{O}_{2 \text { photo }} t}$ and $J_{\mathrm{O}_{2 \text { resp }} t}$ increased when dark fraction was connected. Regarding effect of different nitrogen source, a complex effect was emphasized. When the dark loop was connected, productivity loss in ammonium medium was found larger than with nitrate medium. At this stage this result is difficult to explain. One hypothesis should be a modification of the cellular energetics that could affect directly, or indirectly, the respiration activity or photosynthetic efficiency. This is indeed also known that the N-source changes the yield of oxygen production per unit of biomass. So, this could also result in a different influence of the dark fraction on the overall metabolic response.

\section{Conclusion}

The negative impact of design dark fraction on the global performance of a PBR was established (47\% productivity loss for $f_{\mathrm{d}}=30 \%$ and $t_{\mathrm{d}}=300 \mathrm{~s}$ ). While increasing its volume and the dark residence time, the biomass productivity loss increased. Our analysis showed that this could be attributed to an increase of respiratory activity with increased dark residence time. However, when comparing to some studies on light/dark cycles effect, photosynthetic activity could also be affected. Further investigations are then requested for the complete explanation of the metabolic response implied in microalgal culture systems presenting design dark fraction.

Acknowledgements This research did not receive any specific grant from funding agencies in the public, commercial, or not-for-profit sectors.

\section{Compliance with ethical standards}

Conflict of interest The authors declare that they have no conflict of interest. 


\section{References}

1. Béchet Q, Shilton A, Guieysse B (2013) Modeling the effects of light and temperature on algae growth: state of the art and critical assessment for productivity prediction during outdoor cultivation. Biotechnol Adv 31(8):1648-1663. https://doi.org/10.1016/j.biote chadv.2013.08.014

2. Beijerinck MW (1890) Culturversuche mit Zoochlorellen, Lichenengonidien und anderen niederen Algen. Botanische Zeitung 47:725-739, 741-754, 757-768, 781-785

3. Bold HC (1949) The morphology of Chlamydomonas chlamydogama, Sp. Nov. Bull Torrey Bot Club 76(2):101-108. https ://doi.org/10.2307/2482218

4. Blanken W, Magalhães A, Sebestyén P, Rinzema A, Wijffels RH, Janssen M (2017) Microalgal biofilm growth under day-night cycles. Algal Res 21:16-26

5. Cornet J-F, Dussap C-G (2009) A simple and reliable formula for assessment of maximum volumetric productivities in photobioreactors. Biotechnol Prog 25(2):424-435. https://doi.org/10.1002/ btpr. 138

6. Cornet J-F, Dussap CG, Gros J-B (1998) Kinetics and energetics of photosynthetic micro-organisms in photobioreactors. In: Scheper T (ed) Bioprocess and algae reactor technology, apoptosis. Advances in biochemical engineering biotechnology. Springer, Berlin, pp 153-224. https://doi.org/10.1007/BFb0102299

7. Graham PJ, Nguyen B, Burdyny T, Sinton D (2017) A penalty on photosynthetic growth in fluctuating light. Sci Rep 7:12513. https ://doi.org/10.1038/s41598-017-12923-1

8. Janssen M (2002) Cultivation of microalgae: effect of light/dark cycles on biomass yield. 2002. Thèse de Doctorat. Université de Wageningen

9. Kandilian R, Pruvost J, Artu A, Lemasson C, Legrand J, Pilon L (2016) Comparison of experimentally and theoretically determined radiation characteristics of photosynthetic microorganisms. J Quant Spectrosc Radiat Transf 175(mai):30-45. https:// doi.org/10.1016/j.jqsrt.2016.01.031

10. Kim G, Mujtaba G, Lee K (2016) Effects of nitrogen sources on cell growth and biochemical composition of marine chlorophyte Tetraselmis sp. for lipid production. Algae 31:257-266

11. Kliphuis AMJ, Janssen M, van den End EJ, Martens DE, Wijffels RH (2011) Light respiration in chlorella sorokiniana. J Appl Phycol 23(6):935-947. https://doi.org/10.1007/s10811-010-9614-7

12. Podevin M, De Francisci D, Holdt SL, Angelidaki I (2015) Effect of nitrogen source and acclimatization on specific growth rates of microalgae determined by a high-throughput in vivo microplate autofluorescence method. J Appl Phycol 27(4):1415-1423. https ://doi.org/10.1007/s10811-014-0468-2

13. Pruvost J, Cornet JF, Le Borgne F, Goetz V, Legrand J (2015) Theoretical investigation of microalgae culture in the light changing conditions of solar photobioreactor production and comparison with cyanobacteria. Algal Res 10:87-99. https://doi.org/10.1016/j. algal.2015.04.005 (juillet)

14. Pruvost J, Le Borgne F, Artu A, Legrand J (2017) Development of a thin-film solar photobioreactor with high biomass volumetric productivity (AlgoFilm@) based on process intensification principles. Algal Res 21:120-137. https://doi.org/10.1016/j.algal .2016.10.012 (janvier)

15. Pruvost J, Cornet J (2012) Knowledge models for the engineering and optimization of photobioreactors. In: Posten C, Walter C (eds) Microalgal biotechnology: potential and production. Walter de Gruyter, Berlin, pp 181-224

16. Pruvost J, Le Borgne F, Artu A, Cornet J-F, Legrand J (2016) Chapter five-industrial photobioreactors and scale-up concepts. In: Legrand J (ed) Advances in chemical engineering. Photobioreaction engineering, vol 48. Academic Press, Cambridge, pp 257-310

17. Richmond A (2004) Handbook of microalgal culture: applied phycology and biotechnology, 2nd edn. Blackwell science, Hoboken

18. Ritchie RJ (2006) Consistent sets of spectrophotometric chlorophyll equations for acetone, methanol and ethanol solvents. Photosynth Res 89(1):27-41. https://doi.org/10.1007/s1112 0-006-9065-9

19. Sanz-Luque E, Chamizo-Ampudia A, Llamas A, Galvan A, Fernandez E (2015) Understanding nitrate assimilation and its regulation in microalgae. Front Plant Sci. https://doi.org/10.3389/ fpls.2015.00899 (octobre)

20. Souliès A, Legrand J, Marec H, Pruvost J, Castelain C, Burghelea T, Cornet J-F (2016) Investigation and modeling of the effects of light spectrum and incident angle on the growth of Chlorella vulgaris in photobioreactors. Biotechnol Prog 32(2):247-261. https ://doi.org/10.1002/btpr.2244

21. Sueoka Noboru (1960) Mitotic replication of deoxyribonucleic acid in Chlamydomonas reinhardtii. Proc Natl Acad Sci USA 46(1):83-91

22. Takache H, Pruvost J, Cornet J-F (2012) Kinetic modeling of the photosynthetic growth of Chlamydomonas reinhardtii in a photobioreactor. Biotechnol Prog 28(3):681-692. https://doi. org/10.1002/btpr.1545

23. Takache H, Pruvost J, Marec H (2015) Investigation of light/dark cycles effects on the photosynthetic growth of Chlamydomonas reinhardtii in conditions representative of photobioreactor cultivation. Algal Res 8:192-204. https://doi.org/10.1016/j.algal .2015.02.009 (mars)

24. Terry KL (1986) Photosynthesis in modulated light: quantitative dependence of photosynthetic enhancement on flashing rate. Biotechnol Bioeng 28(7):988-995. https://doi.org/10.1002/bit.26028 0709

25. Torzillo G, Seibert M (2013) Hydrogen production by Chlamydomonas reinhardtii. In: Richmond A, Hu Q (eds) Handbook of microalgal culture: applied phycology and biotechnology, 2nd edn. Wiley, Oxford, pp 417-432

Publisher's Note Springer Nature remains neutral with regard to jurisdictional claims in published maps and institutional affiliations. 